\title{
METHOD VALIDATION OF RIFAMPICIN ANALYSIS IN HUMAN PLASMA AND ITS APPLICATION IN BIOEQUIVALENCE STUDY
}

\section{ENDANG LUKITANINGSIH ${ }^{*}$, FATHUL JANNAH², RATNA BUDHI PEBRIANA1, RATNA DEWI PUSPITA4, TAUFIQUROHMAN ${ }^{4}$, ZULLIES IKAWATI ${ }^{3}$}

\begin{abstract}
${ }^{1}$ Department of Pharmaceutical Chemistry, Faculty of Pharmacy, Gadjah Mada University, Jl. Sekip Utara, Yogyakarta, 55281, Indonesia, ${ }^{2}$ Laboratory of Advanced Pharmaceutical Sciences, Faculty of Pharmacy, Gadjah Mada University, Jl. Sekip Utara, Yogyakarta, 55281, Indonesia, ${ }^{3}$ Department of Pharmacology and Clinical Pharmacy, Faculty of Pharmacy, Gadjah Mada University, Jl. Sekip Utara, Yogyakarta, 55281, Indonesia, ${ }^{4}$ UGM Hospital, Jl. Kabupaten (Lingkar Utara), Kronggahan, Trihanggo, Gamping, Sleman, Yogyakarta 55291, Indonesia

Email: lukitaningsih_end@ugm.ac.id

Received: 16 Mar 2019, Revised and Accepted: 24 May 2019
\end{abstract}

\section{ABSTRACT}

Objective: This research aims to validate the method for rifampicin analysis in plasma by using High-Performance Liquid Chromatography (HPLC) that can be used to study the bioequivalence of a generic tablet of rifampicin $450 \mathrm{mg}$ "X" marketed in Indonesia.

Methods: Bioequivalence test was analysed using HPLC equipped with UV-Vis detector at $377 \mathrm{~nm}$. The mobile phase used was acetonitrilephosphate buffer $\mathrm{pH} 6.8$ (45:55) delivered at a flow rate of $1.5 \mathrm{ml} / \mathrm{min}$. Bioequivalence test was conducted on a limited number of subjects ( $\mathrm{n}=8$ ). The subjects were divided into two groups randomly. The pharmacokinetic profiles of the test tablet and reference tablet were statistically calculated using SPSS program to see the test tablet and reference tablet were bioequivalence or not.

Results: The developed HPLC method for rifampicin analysis in plasma was sufficiently valid based on the International Conference on Harmonization (ICH) and European Medicines Agency (EMA) guideline, with precision and accuracy values were \% Relative Standard Deviation (\% $\mathrm{RSD}=1.40-13.04)$ and \% Recovery (86.24-102.13), respectively. Meanwhile, the method was linear over studied concentration 0.05 to 10.26 $\mu \mathrm{g} / \mathrm{ml}$ ) with a coefficient of determination $\left(\mathrm{R}^{2}\right)=0.9984$. The method also had good stability and sensitivity. The result of statistical calculation showed that the generic rifampicin tablet $X$ was bioequivalence toward the reference tablet Rimactan $450 \mathrm{mg}$.

Conclusion: The test rifampicin tablet that was, the generic tablet " $\mathrm{X}$ " was bioequivalence toward the reference rifampicin tablet "Rimactan".

Keywords: Rifampicin, Bioanalysis, Validation, Bioequivalence, Plasma

(C) 2019 The Authors. Published by Innovare Academic Sciences Pvt Ltd. This is an open access article under the CC BY license (http://creativecommons.org/licenses/by/4.0/) DOI: http://dx.doi.org/10.22159/ijap.2019v11i4.33107

\section{INTRODUCTION}

Tuberculosis (TB) is an infectious disease, ranks as the second killer after human immunodeficiency virus (HIV) worldwide. In 2012, there were 8.6 million new TB cases and 1.3 million TB deaths reported by WHO. In Indonesia, the prevalence of TB was 257 per 100.000 people in 2013. TB is caused by the bacillus Mycobacterium tuberculosis. Rifampicin is a macrocyclic antibiotic derived from Streptomyces mediterraneil used as the first line anti-TB drug together with Isoniazid (INH), Ethambutol, and Pyrazinamide [1, 2, 3]. Rifampicin acts as anti-TB by inhibiting the DNA-dependent RNA polymerase of the bacterial cells [4].

As a consequence of the high prevalence of TB is high demand for TB drug. To overcome this problem, pharmaceutical industries produce a copy of rifampicin drug. Rifampicin is available in some oral dosage forms and strength: $75,150,300,450 \mathrm{mg}$, and $600 \mathrm{mg}$ capsule or tablet [5]. After the administration of the $600 \mathrm{mg}$ dosage form, the maximum plasma concentration (Cmax) of rifampicin is targeted to be $8-24 \mu \mathrm{g} / \mathrm{ml}$. The lower or higher value of Cmax will influence the expected pharmacological effect [6]. Since the bioavailability of the drug is highly affected by the formulation of the dosage form, so it is important to establish bioavailability and bioequivalence study to every new copy of rifampicin drug. Furthermore, a different formulation of marketing rifampicin dosage forms itself delivered variability in the bioavailability [7]. Therefore, it is necessary to develop accurate, sensitive, reproducible, and simple analytical method to support the study.

Several analytical methods for the determination of rifampicin in plasma are already reported, including HPTLC [8], LC-MS [9], LCMS/MS [10, 11] and HPLC or UPLC-UV method [12, 13]. Those methods have some drawbacks so that those unsuitable and cannot be directly implemented in our Advanced Pharmaceuticals Science Laboratory as part of bioavailability and bioequivalence testing service provided. The previous method was considered expensive, complicated, and time-consuming. So, we developed an accurate, precise, cheaper, and simpler HPLC-UV method to analyze rifampicin in human plasma. This method involves deproteination and liquidliquid extraction prior to HPLC analysis with C18 column and was validated as per the European Medicines Agency (EMA) guideline on Bioanalytical method validation [14].

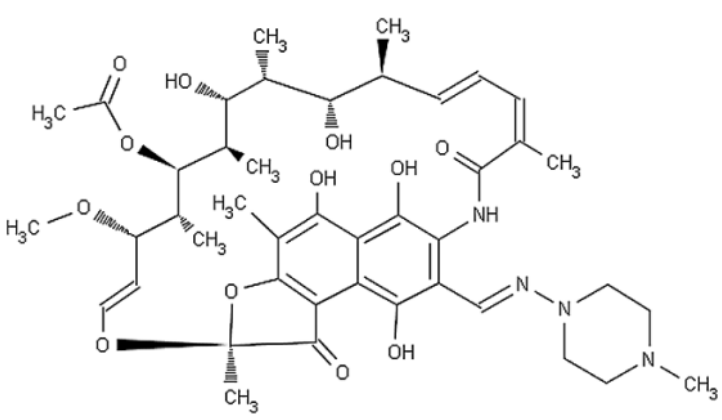

Fig. 1: Chemical structure of rifampicin

\section{MATERIALS AND METHODS}

\section{Chemicals and materials}

Rifampicin standard $¥ 90.0 \%$ from Sigma-Aldrich (Dorset, UK), Rifampicin generic tablet " $X$ " 450 mg from Indonesia, Rimactan Tablet $450 \mathrm{mg}$ from Novartis. Triethanolamine, phosphoric acid and glacial acetic acid were obtained from Merck (Darmstadt, Germany). Methanol and acetonitrile HPLC grade were purchased from Merck (Darmstadt, Germany). Human plasma was from the Indonesian Red Cross. 


\section{Equipments}

HPLC was equipped with UV-Vis L-2420, pump L-2130 and Lachrom C18 column ( 250 X $4.6 \mathrm{~mm} ; 5 \mu \mathrm{m}$ ) from Hitachi (Japan). Refrigerated centrifuge (Dynamica Velocity 18R, UK), vortex thermolyne 16700 mixer (USA), semi microbalance (OHAUS EX225D, USA), deep freezer (NUAIRE NU-9483 E, USA), and glassware.

\section{Suitability of HPLC system for rifampicin analysis}

An amount of $20 \mu \mathrm{l}$ of rifampicin standard solution $(2.5 \mu \mathrm{g} / \mathrm{ml})$ was injected into HPLC (operated as condition in table 1) for eight times. The chromatograms were evaluated and calculated percentage relative standard deviation (\% RSD) of retention time (RT) and resolution factor (Rs), tailing factor and plate theoretic number $(\mathrm{N})$. The system was suitable for rifampicin analysis if all parameters met to the acceptance criteria as in ICH and EMA guidelines $[15,16]$.

Table 1: Operational condition of HPLC used for rifampicin analysis in plasma (refers to the USP 30 Pharmacopeia with slight modification [17])

\begin{tabular}{ll}
\hline Stationary phase & C18 $(\mathbf{2 5} \mathbf{~ c m}, \mathbf{0 . 4} \mathbf{~ c m}$ i.d., $\mathbf{0 . 5} \boldsymbol{\mu m}$ particle sizes $)$ \\
\hline Mobile Phase & A: Acetonitrile \\
& B: Phosphate buffer solution $(\mathrm{pH} 6.8)$ \\
Flow Rate & Composition A: B (45:55) \\
Detector & $1.5 \mathrm{ml} / \mathrm{min}$ \\
Volume of injection & UV spectrophotometer at $377 \mathrm{~nm}$ \\
\hline
\end{tabular}

\section{Spiked human plasma preparation}

As much as $750 \mu \mathrm{l}$ of plasma was added by rifampicin standard as needed and $1 \mathrm{ml}$ of acetonitrile, then centrifuged in 10.000-12.000 rpm for $10 \mathrm{~min}$. The supernatant was taken and repeated the extraction process once again. The acetonitrile phase was collected and evaporated until dryness. The precipitate was re-suspended in the mobile phase $(1 \mathrm{ml})$ and filtered using $0.45 \mu \mathrm{m}$ filter syringe prior injected into the HPLC.

\section{Method validation}

Method validation was needed to assure that the developed method was capable for producing the reliable and consistent result, as well as fits to its intended purposes. In this study, method validation was conducted by determining several parameters including selectivity, carry over, linearity, sensitivity, precision, accuracy, dilution integrity, stability and ruggedness which were worked in acceptance of ICH and EMA guidelines $[18,14,19]$.

\section{Selectivity}

Selectivity of method was proven by comparing the chromatogram of the mobile phase, plasma blank, and spiked plasma with standard rifampicin. If there was no signal at the retention time of rifampicin, it can be concluded that the method was selective. The selectivity was also calculated by calculating Resolution Factor (Rs). Acceptance criteria for selectivity parameter was Rs $>2$ [20].

\section{Carry-over}

Carryover was conducted by injecting the blank sample after injecting the standard solution at the high concentration (more than the upper limit of quantification). Acceptance criteria: Carryover in the blank sample following the high concentration standard should not be greater than $20 \%$ of the lower limit of quantification (LLOQ) and $5 \%$ of the internal standard $[21,14]$.

\section{Linearity of the calibration curve}

Calibration curve was prepared by adding a series concentration of rifampicin standards into blank plasma until having concentration of $0.05 ; 0.10 ; 0.50 ; 1.00 ; 2.50 ; 5.00 ; 7.50$; and $10.00 \mu \mathrm{g} / \mathrm{ml}$. The peak area of each concentration was then plotted on their concentration. A linear regression curve was made in formula $\mathrm{Y}=\mathrm{BX}+\mathrm{A} ; \mathrm{X}$ was the concentration of rifampicin and $Y$ was peak area. Coefficient of correlation $(R)$ and coefficient of determination $\left(R^{2}\right)$ was calculated and evaluated according to the acceptance criteria including R-value $\geq$ 0.999 and $\mathrm{R}^{2}$ value $\geq 0.997[20,21]$. Moreover, it had to meet the acceptance criteria of EMA, namely the back-calculated concentrations of the calibration standards should be within $\pm 15 \%$ of the nominal value, except for the LLOQ for which it should be within $\pm 20 \%$. At least $75 \%$ of the calibration standards, with a minimum of six calibration standard levels, must fulfill this criterion. LLOQ sample should be at least 5 times the signal a blank sample [14].

\section{Sensitivity}

Sensitivity was determined as the limit of determination (LOD) and limit of Quantification (LOQ). LOD was defined as the minimum concentration of rifampicin that can be detected properly by the system of analysis, whilst LOQ was defined as the minimum concentration of rifampicin that can be quantified properly by the system of analysis. LOD and LOQ was measured with the formula:

$$
\begin{aligned}
& \mathrm{LOD}=\frac{3 \mathrm{SD}}{\mathrm{B}} \\
& \mathrm{LOQ}=\frac{10 \mathrm{SD}}{\mathrm{B}}
\end{aligned}
$$

SD: standard deviation of intercept or standard deviation of the lowest concentration of standard rifampicin detected in 10 triplicate analysis

B: the slope of the calibration curve

\section{Accuracy}

Accuracy was carried out by measuring the percent of recovery or a percent of the nominal value. Accuracy was measured by adding a number of rifampicin standard in plasma and then analysed. Accuracy should be evaluated to the values of the QC samples obtained within a single run (the within-run accuracy) and in different runs (the between-run accuracy) [14, 22, 23].

\section{Within-run accuracy}

Within-run accuracy was carried out by analysing in a single-run of 5 samples per concentration at 4 different concentrations representing low, middle, and high concentrations. The mean calculated concentration should be within 15\%, except for the low concentration should be within $20 \%$ of the nominal value [14].

\section{Between-run accuracy}

Between-run accuracy was conducted at least on 4 different concentrations (representing low, middle, and high concentrations) and analysed on at least two different days. The mean of calculated concentration should be within $15 \%$, except for the low concentration which should be within $20 \%$ of the nominal value [14].

\section{Precision}

Precision parameters were expressed as the percentage relative standard deviation (\% RSD) of calculated concentration. There were two precision parameters, namely within-run precision and between-run precision [14]. 


\section{Within-run precision}

Within-run precision was conducted at least 5 samples per concentrations (representing low, middle, and high concentrations) in a single run. For within-run precision, \% RSD value should not exceed $15 \%$ for the middle and high concentration, except for the LLOQ which should not exceed $20 \%$.

\section{Between-run precision}

Between-run precision was conducted using the same concentration as in the determination of within-run precision. However, it was analysed on two different days. \% RSD value for between-run precision should not exceed $15 \%$ for the QC samples, except for the LLOQ which should not exceed $20 \%$.

\section{Dilution integrity}

This parameter was to evaluate the effect of dilution on the precision and accuracy parameters. It was carried out by diluting $15 \mu \mathrm{g} / \mathrm{ml}$ of standard solution in 2 and 10 times dilution factors. Acceptance criteria: \%RSD of accuracy and precision should be within the set criteria or $\pm 15 \%$ [14].

\section{Stability}

Stability was measured to find out the effects of several treatments during analysis on the result of the measurement. In this case, stability test was measured during storage at the room temperature, $-20{ }^{\circ} \mathrm{C}$, and $-80{ }^{\circ} \mathrm{C}$, as well as during delivery from the location of sample collection (UGM Hospital) to the laboratory. The acceptance criteria: the mean of concentration at each assessment should be within $\pm 15 \%$ of the nominal concentration [14].

\section{Ruggedness}

Ruggedness was calculated by comparing the result of the determination of spiked plasma in the concentration of $5 \mu \mathrm{g} / \mathrm{ml}$, which was conducted by the researcher, and the analysis result from another laboratory. After then, a statistical calculation was conducted by using the $t$-test. If $p>0.05$, the average difference from both results was not significant.

\section{Bioequivalence study of rifampicin}

\section{Ethical clearance}

This research was carried out under the Declaration of Helsinki [23], Good Clinical Practice [24] and Good Laboratory Practice [25]. The protocol of research, informed consent of the patient, and guidance of calling participants must be reviewed and got the consent of ethical clearance from an ethics commission (medical and health research ethics committee) of Faculty of Medicine, Universitas Gadjah Mada before being applied in this research. The number of ethical clearance for doing this research is KE/FK/602/EC/2015.

\section{Study design}

The study design was a randomized cross over using 8 (eight) subjects. The administration of the test drugs between stage 1 and stage 2 on the subjects was carried out in a washout period for $1 \mathrm{w}$. During this period, the test subjects must not consume any drugs, including herbs [26, 27].

\section{Inclusion and exclusion criteria}

According to the guideline of good clinical practice, the inclusion and exclusion criteria had been set before selecting subjects. Inclusion criteria were healthy volunteers, male or female, $18-55$ y old, not a cigarette smoker, not consuming any drugs in a week before the test. Subjects should be having normal weight with body mass index (BMI) around 18-25. Health condition should be proved by a clinical laboratory test. Female subjects were not pregnant women and proved by the pregnancy test. Exclusion criteria were women who are pregnant, breastfeeding and consuming contraception pills. People were having contraindication and allergy with rifampicin, smoking and drinking alcohol, having a history of drug and alcohol addiction as well cannot be as subject $[26,27]$.
Before starting this research, subjects were given an explanation of the informed consent and opportunity to ask for as much as an explanation. After then, the subjects were asked to sign the informed consent of joining the research [14]. Volunteers who were willing to participate as the subjects should follow the health examination, including laboratory test of urine and blood as well as liver and kidney function. Urine examination was carried out to examine the reduction of glucose, urobilin, bilirubin, albumin, and sediment. Blood examination included hemoglobin, hematocrit, the amount and types of leukocytes, erythrocyte, and total protein. Examination of liver functional covered bilirubin (total, direct and indirect), alanine transaminase (ALT) and aspartate transaminase (AST), while kidney examination included proteinuria, serum urea and serum creatinine. Additionally, the subjects were not allowed to take any medication one week before and during this pharmacokinetic research.

\section{Conditioning subject and drug admission}

The night before the test, the subjects were asked to come to UGM hospital no later than 7:00 p. m. for staying overnight. The night before the bioequivalence test was conducted, each subject was asked to start fasting at 9:00 p. m.; drinking water was allowed in ad libitum. Subjects were also not allowed to consume any drinks containing alcohol, caffeine, tea, and chocolate at least $24 \mathrm{~h}$ before the administration of rifampicin until the test I complete (the latest blood sampling was conducted).

At 7:00 a. $\mathrm{m}$., the blood sample $(7 \mathrm{ml})$ was taken as a blank, followed by drug administration of $450 \mathrm{mg}$ per dosage with $250 \mathrm{ml}$ water. And then, the blood sample was serially taken at 0 and $30 \mathrm{~min}$, and $1 ; 1.5 ; 2 ; 2.5 ; 3$; $3.5 ; 4 ; 6,8 ; 10 ; 12 ; 18$ and $24 \mathrm{~h}$ after consuming the drug using the vacutainer that contained heparin. Plasma was separated and stored in a frozen temperature $\left(-20^{\circ} \mathrm{C}\right)$ in a glass tube in an upright state and wrapped in aluminum (to prevent contact with rubber caps and photodecomposition) until the analysis was carried out.

The subjects were given breakfast with standardized composition 4 $\mathrm{h}$ after drug administration. They were allowed to drink water anytime except 1 hour before and $2 \mathrm{~h}$ after drug administration. They were given lunch and dinner $8 \mathrm{~h}$ and $12 \mathrm{~h}$ after drug administration. They were also allowed to consume other foods of which composition met the standard and did not interact with drugs or disturb the normal function of gastrointestinal, liver, or kidney. Besides food, all-day physical activities have also been standardized to reduce the variability among subjects that may occur, such as motility and blood flow in the gastrointestinal tract. During the research, every complaint regarding side effects of the drug will get proper attention and treatment from the medical person in charge. Clinical side effects of rifampicin that need to be taken into account were nausea, vomiting, anorexia, diarrhea, influenza syndrome, respiratory disorder, collapse and shock, hemolytic anemia, acute renal failure, urticaria, and impaired liver function.

\section{Bioanalysis of rifampicin in plasma}

Determination of rifampicin in plasma was carried out by measuring parent compound using HPLC (High-Performance Liquid Chromatography) based on the modified Pharmacopeia USP 30 method [17]. Determination of rifampicin in plasma samples was done using a validated bioanalytical method, as in the method above and followed by measuring rifampicin concentration using calibration curve.

\section{Parameters of pharmacokinetics that should be evaluated}

The relationship between the area under the curve (AUC) of chromatograms and the sampling time used to assess the amount and speed of absorption, distribution and elimination. Bioavailability parameters of the blood sample used for analysis included the area under curve toward the duration from 0 to the last time of sampling (AUCt) and calculated using the trapezoidal method; AUC from time 0 until infinite time (AUCO); maximum concentration of rifampicin in observed plasma (Cmax); time after drug administration at which maximum concentration occured (tmax) and half-time of drug elimination $(\mathrm{t} 1 / 2)$. 
Pharmacokinetic analysis of rifampicin was carried out using noncompartmental model. $\mathrm{C}_{\text {maks }}$ and $\mathrm{t}_{\max }$ values were taken from the real values of drug level in plasma toward the time on each subject. AUC, firstorder rate constant for elimination of drug from the central compartment of the pharmacokinetic model $\left(\mathrm{k}_{\mathrm{el}}\right), \mathrm{t}_{1 / 2}$, mean of residence time (MRT), apparent volume of distribution at steady state $\left.\left(\mathrm{V}_{\mathrm{d}(\mathrm{ss}}\right)\right)$ and clearance $(\mathrm{Cl})$ were calculated using PK's function software (under Microsoft Excel). Level-dependent data were AUC and $\mathrm{C}_{\max }$, which were transformed into logarithmic (ln) form first to find out the normality of data distribution. Pharmacokinetics parameter calculated from both drugs (rifampicin tablet test and rifampicin tablet reference) was analysed based on variance (ANOVA) with a confidence level of $90 \%[24$, 25]. The statistics software used was SPSS version 10.00.

\section{Bioequivalence parameter}

Test drug (test $=\mathrm{T}$ ) and comparative drug (reference $=\mathrm{R}$ ) were said to be bioequivalence if:

A. Ratio of the average geometric value of $\mathrm{AUC}_{\mathrm{T}} / \mathrm{AUC}_{\mathrm{R}}=1.00$, with $90 \% \mathrm{CI}=80.00-125.00 \%$.

B. Ratio of the average geometric value of $\left(\mathrm{C}_{\max }\right)_{\mathrm{T}} /\left(\mathrm{C}_{\max }\right)_{\mathrm{R}}=1.00$, with $90 \% \mathrm{CI}=75.00-130.00 \%$

\section{RESULTS AND DISCUSSION}

\section{System suitability test}

Using HPLC operational condition as in table 1, the system suitability test was conducted using standard rifampicin. The result of the system suitability test was summarized in table 2 .

Based on the result in table 2, it can be seen that HPLC condition was suitable for rifampicin analysis since it fulfilled the acceptance criteria [16], namely \% RSD of retention time and area of $0.90 \%$ and $1.62 \%$ (less than $2 \%$ ), resolution factor of $4.23 \pm 0.73$ (more than 2), tailing factor $1.13 \pm 0.01$ (less than 1.5 ) and theoretical plate number of $7025 \pm 64$ (more than 2000). Using an HPLC system, then the method of rifampicin analysis in plasma was validated.

\section{Selectivity}

The following fig. 2 revealed chromatograms of the mobile phase, plasma blank without rifampicin, and spiked plasma with rifampicin. There was no peak that had the same retention time as rifampicin, in both blank chromatogram (B) and mobile phase chromatogram (A). Thus, it can be concluded that the method was selective, which was able to distinguish the analytic signal from an interference signal.

Table 2: System suitability test of rifampicin analysis using HPLC

\begin{tabular}{|c|c|c|c|c|c|c|c|c|c|}
\hline \multirow[t]{2}{*}{ Parameter } & \multicolumn{6}{|c|}{ Replication } & \multirow[t]{2}{*}{ Mean } & \multirow[t]{2}{*}{ \%RSD } & \multirow[t]{2}{*}{ Acceptance criteria } \\
\hline & 1 & 2 & 3 & 4 & 5 & 6 & & & \\
\hline Retention time (min) & 4.37 & 4.32 & 4.32 & 4.29 & 4.29 & 4.27 & 4.32 & 0.90 & $\mathrm{RSD} \leq 2 \%$ \\
\hline Area & 4537 & 46414 & 44979 & 44438 & 45386 & 44813 & 45321 & 1.62 & $\mathrm{RSD} \leq 2 \%$ \\
\hline Tailing factor (Tf) & 1.13 & 1.12 & 1.13 & 1.13 & 1.12 & 1.15 & 1.13 & 0.09 & $<1.5$ \\
\hline Theoretical plate number $(\mathrm{N})$ & 7112 & 7065 & 7061 & 6992 & 6956 & 6962 & 7025 & 0.91 & $\geq 2000$ \\
\hline Capacity factor $\left(\mathrm{k}^{\prime}\right)$ & 435.67 & 433.67 & 431.00 & 428.33 & 427.67 & 426.33 & 430.45 & 0.85 & - \\
\hline Resolution factor (Rs) & 5.70 & 3.97 & 3.86 & 4.03 & 3.92 & 3.87 & 4.23 & 17.17 & $\geq 2$ \\
\hline
\end{tabular}

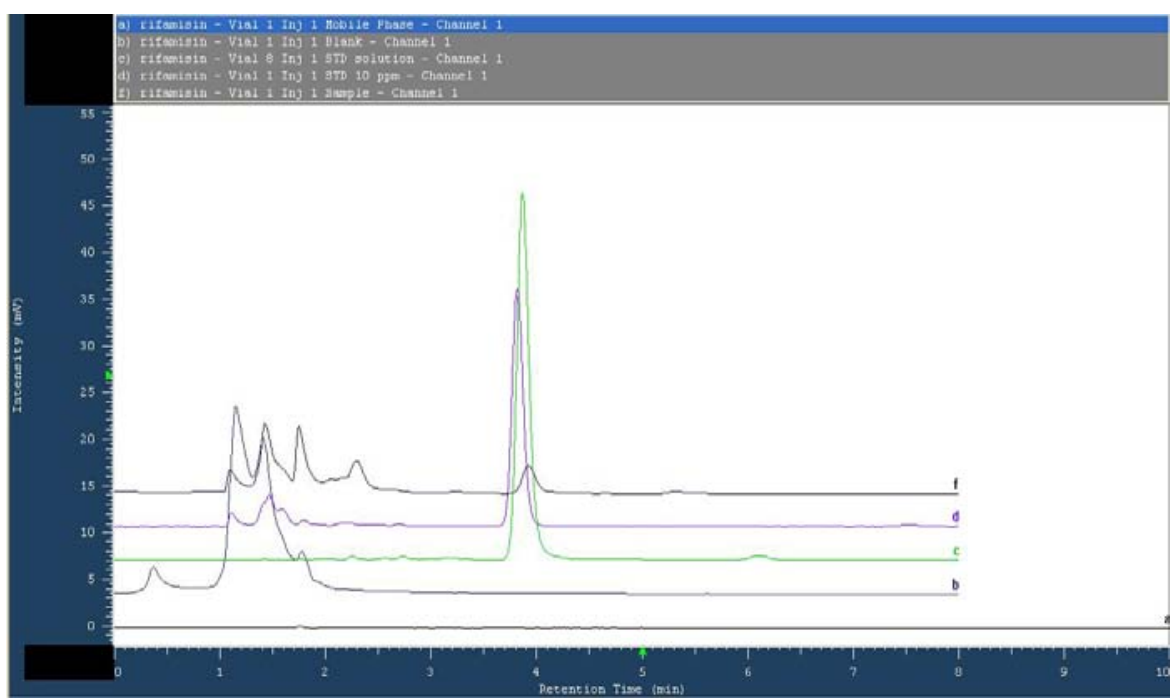

Fig. 2: Chromatograms of mobile phase (a); plasma blank (b); standard solution of rifampicin (c); plasma spiked with $10 \mu \mathrm{g} / \mathrm{ml} \mathrm{of}$ rifampicin (d); plasma sample of subject ( $f$ )

Table 3: Calibration curve of rifampicin analysis

\begin{tabular}{ll}
\hline Concentration of rifampicin $(\boldsymbol{\mu g} / \mathbf{m l})$ & Area \\
\hline 0.051 & \% error \\
0.103 & 1031 \\
0.518 & 19.06 \\
1.028 & 20.01 \\
2.565 & 14.38 \\
5.129 & 2.91 \\
7.694 & 1.13 \\
10.259 & 3.40 \\
\hline
\end{tabular}

Note: each concentration was injected into the HPLC system in triplicate analysis 


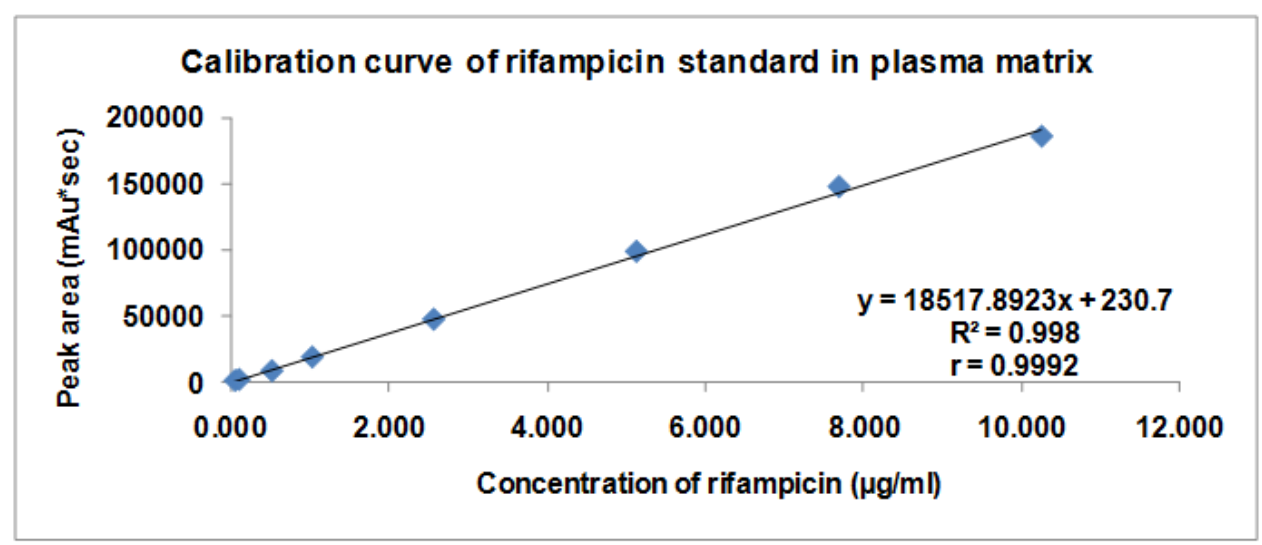

Fig. 3: Calibration curve of rifampicin in plasma matrix

\section{Calibration curve and sensitivity}

The calibration curve, the relationship between standard concentration and chromatogram area has made, and the result was represented in table 3 below.

The regression equation of calibration curve (fig. 3) was found to be $\mathrm{Y}=18517.8923 \mathrm{X}+230.70$; with $\mathrm{r}=0.9992$ and $\mathrm{R}^{2}=0.998$. Linear regression equation met the requirement of the valid method since the calculated concentration has \% error within 15\% [14], except for low concentration in the value of $20 \%$. More than $75 \%$ of the calculated concentration have \% error of less than $15 \%$. Using this linear regression equation, rifampicin in plasma can be calculated after the chromatogram area was obtained.

Sensitivity of the analytical method was evaluated by measuring limit of detection (LOD) and limit of quantification (LOQ) using formula stated in the method section. SD was the standard deviation of the chromatogram area of spiked plasma with rifampicin in low concentration $(0.05 \mu \mathrm{g} / \mathrm{ml})$ in 8 replicate analysis. B was the intercept value of the calibration curve $(230.70)$. The SD obtained from this research was 166.582. Therefore, LOD and LOQ values were 0.015 and $0.077 \mu \mathrm{g} / \mathrm{ml}$ respectively. The sensitivity of this method was better than sensitivity found in other methods [29] which had LOD and LOQ values were 0.110 and $0.332 \mu \mathrm{g} / \mathrm{ml}$, respectively.

\section{Carryover test}

There was no rifampicin peak in the chromatogram of mobile phase that it injected after injection of rifampicin in high concentration.

\section{Accuracy and precision}

Accuracy parameter was expressed as \% recovery and carried out at 4 level concentrations in 5 replications per concentration $(0.050$; $0.150 ; 5.000 ; 8.000 \mu \mathrm{g} / \mathrm{ml})$. A detailed recovery data generated for the assay validation was represented in table 4 and table 5 below.

Table 4: Within-run accuracy

\begin{tabular}{lll}
\hline Actual concentration $(\boldsymbol{\mu g}(\boldsymbol{\mu g} / \mathbf{m l})$ & Calculated concentration $(\boldsymbol{\mu g} / \mathbf{m l})$ & Recovery $(\%)$ \\
\hline 0.052 & 0.048 & $91.95 \pm 7.54$ \\
0.155 & 0.1334 & $86.24 \pm 13.04$ \\
5.129 & 5.131 & $100.03 \pm 2.56$ \\
8.207 & 8.382 & $102.13 \pm 3.25$ \\
\hline
\end{tabular}

Note: Recovery was represented as mean \pm RSD in 5 replicates for each concentration

Table 5: Between-run accuracy

\begin{tabular}{|c|c|c|c|c|}
\hline \multirow[t]{2}{*}{ Actual concentration $(\mu \mathrm{g} / \mathrm{ml})$} & \multicolumn{3}{|c|}{ Recovery per Day (\%) } & \multirow{2}{*}{ Recovery between-run (\%) } \\
\hline & Day-1 & Day-2 & Day-3 & \\
\hline 0.052 & 91.95 & 88.55 & 111.46 & $97.32 \pm 10.37$ \\
\hline 0.155 & 86.24 & 105.00 & 87.59 & $92.94 \pm 9.19$ \\
\hline 5.129 & 100.03 & 97.34 & 96.94 & $98.10 \pm 1.40$ \\
\hline 8.207 & 102.13 & 91.68 & 98.16 & $97.32 \pm 4.43$ \\
\hline
\end{tabular}

Note: Between-run accuracy was expressed as recovery (\%) and represented as mean \pm RSD of 4 level concentration in 5 replicate determinations per concentration in 3 different days.

Based on table 4 and table 5 , it showed that the analytical method tested met the criteria of within-run accuracy since its recovery was about 86.24-102.13\% (acceptance criteria 85-115\%) and all RSDs were less than $15 \%$. Between-run accuracy also met the criteria since its recovery from three different days was between 86.24$111.46 \%$ and all RSDs were less than 15\%. Both within-run and between-run precisions also met the criteria because RSD of within run was 2.56-13.04\% (acceptance criteria within 15\%), and RSD between-run was 1.40-10.37\% (acceptance criteria within 15\%). Thus, the proposed method of analysis met the criteria of the valid analytical method and can be used for regular analysis. The overall recovery and precision parameters were within the acceptability criteria of Bioanalysis validation procedure from the European Medicines Agency (EMA) and the Food and Drug Administration (FDA) guideline [14, 29].

\section{Dilution integrity}

Dilution integrity was evaluated to ensure that there was no significant effect of the dilution process in determining rifampicin level in plasma [14]. In this research, the effect of dilution has been evaluated using $15 \mu \mathrm{g} / \mathrm{ml}$ of standard solution diluted twice and ten times. The result was summarized in table 6 . It can be concluded that there was no significant effect of the dilution process on the result generated from this method. 
Table 6: Result of dilution integrity test

\begin{tabular}{|c|c|c|c|c|}
\hline Standard concentration $(\mu \mathrm{g} / \mathrm{ml})$ & Dilution factor & Actual concentration $(\mu \mathrm{g} / \mathrm{ml})$ & Calculated concentration* $(\mu \mathrm{g} / \mathrm{ml})$ & Significance $^{* *}$ \\
\hline \multirow{3}{*}{15.39} & $0 \mathrm{x}$ & 15.39 & $15.85 \pm 9.28$ & $\mathrm{p}=0.428$ \\
\hline & $2 x$ & 7.70 & $7.74 \pm 3.59$ & \\
\hline & $10 x$ & 1.54 & $1.49 \pm 2.51$ & \\
\hline
\end{tabular}

Note: *Data was represented as mean $\pm \%$ RSD obtained from 5 replicate the analysis for each dilution factor, $* *$ p ( 0.428$)>0.05$; there were no significant differences between actual and calculated concentration

\section{Stability}

Stability test has also been performed in this research. The result can be seen in table 7. Stability test was essential to ensure that the analyte was not broken since it was taken up to the time of analysis [14]. Based on table 7, it can be concluded that the analytical method was stable since the mean calculated concentration at each level and each condition should be within $\pm 15 \%$ of actual concentration or its recovery was about $85-115 \%$.

\section{Ruggedness}

Ruggedness testing has also been carried out in this research. By comparing the analysis result conducted by the researcher toward the analysis result done by other laboratories (in this case was the Indonesian Agency of Drug and Food Monitoring or BPOM in Indonesia), it showed that there were any significant differences among both results, and it still met the criteria of a valid method.

Table 7: Result of stability test

\begin{tabular}{|c|c|c|c|c|c|}
\hline \multirow[t]{2}{*}{ Actual concentration $(\mu \mathrm{g} / \mathrm{ml})$} & \multicolumn{5}{|c|}{ Recovery after treatment* } \\
\hline & $0 h, 25^{\circ} \mathrm{C}$ & $2 h, 25^{\circ} \mathrm{C}$ & $4 h, 25^{\circ} \mathrm{C}$ & $2 \mathrm{~d},-20^{\circ} \mathrm{C}$ & $30 \mathrm{~d},-80^{\circ} \mathrm{C}$ \\
\hline 0.155 & $100 \%$ & $103.66 \%$ & $103.62 \%$ & $93.75 \%$ & $92.20 \%$ \\
\hline 8.207 & $100 \%$ & $93.80 \%$ & $102.78 \%$ & $97.52 \%$ & $106.72 \%$ \\
\hline
\end{tabular}

Note: *Recovery after treatment was represented as mean \pm SD from 5 replicate analysis for each condition
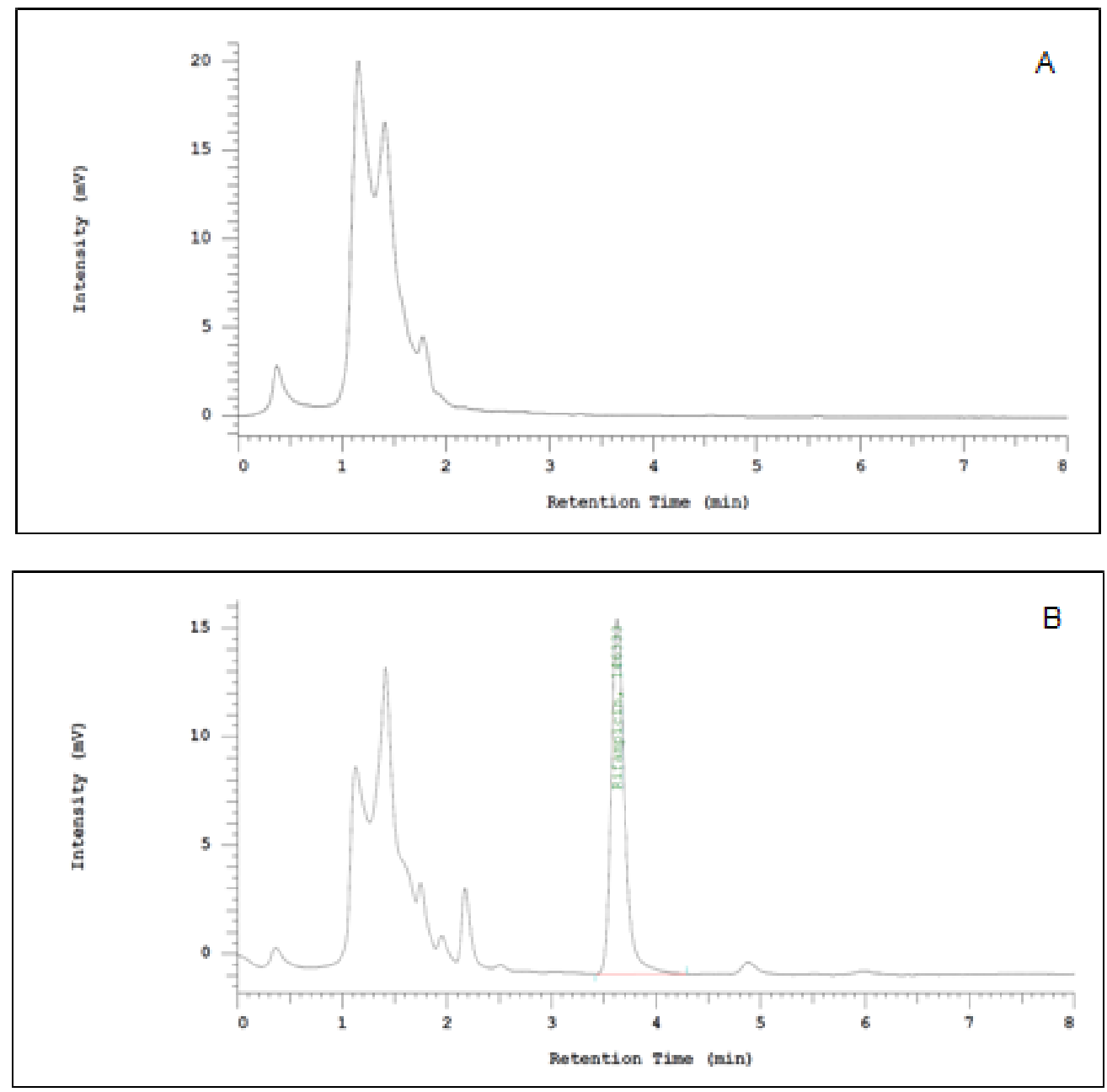

Fig. 4: Chromatograms of blank plasma (A) and sample of the subject in $3 \mathrm{~h}$ after consuming test drug (B) 
Table 8: Result of ruggedness test

\begin{tabular}{llll}
\hline \multicolumn{2}{l}{ Calculated concentration $(\boldsymbol{\mu g} / \mathbf{m l})$} & Significance & Conclusion \\
\cline { 1 - 2 } UGM laboratory & BPOM laboratory & $\mathrm{p}=0.049$ & There was no significant difference in the analysis results in both \\
4.59 & 5.01 & & UGM and BPOM Laboratory. \\
4.62 & 4.80 & & \\
4.68 & 4.89 & & \\
\hline
\end{tabular}

Based on the result of the validation method, it can be concluded that this developed method can be used to analyse rifampicin concentration in the blood plasma for bioequivalence study.

\section{Results of bioequivalence study}

To ensure that there was no interference of endogen matrix found in plasma sample or metabolite of rifampicin, it was necessary to evaluate chromatograms of blank plasma and plasma of subject after consuming rifampicin tablet [28, 30]. Fig. 4 below showed chromatogram of plasma samples from a subject that has given rifampicin orally (B) compared to chromatogram from blank plasma (A). Based on fig. 4, there was no metabolite or other endogenous substance that interfering analysis, so that the method was suitable to be used in bioequivalence study.
Procedure of bioequivalence analysis carried out in this research has been given permission by the Medical and Health Research Ethnics Committee (MHREC), Faculty of Medicine, Gadjah Mada UniversityDR. Sardjito Hospital with number: KE/FK/602/EC/2015.

Based on the analysis result of rifampicin level in plasma (Cp) obtained from subjects $(n=8)$ that have met the criteria as a good subject for bioequivalence test, the average pharmacokinetic parameters of rifampicin generic tablet " $\mathrm{X}$ " and rifampicin reference tablet "R" can be calculated. Fig. 5 below was the pharmacokinetic profile of the two tablets.

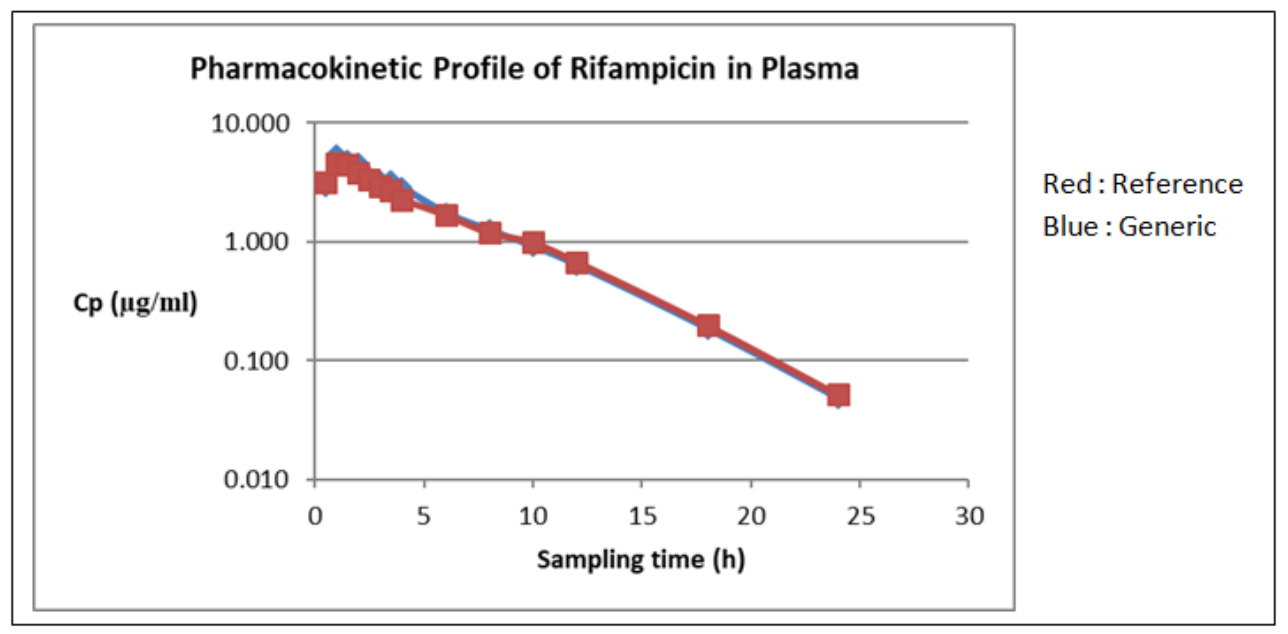

Fig. 5: Pharmacokinetics profile of rifampicin generic Tablet " $X$ " and reference tablet " $R$ "

In table 9, the detail of each pharmacokinetic parameter was presented. In bioequivalence test, pharmacokinetic parameters that should be calculated statistically were AUC, $\mathrm{C}_{\max }$ and $\mathrm{t}_{\max }$. However, the most relevant parameters for bioequivalence test were AUC and $\mathrm{C}_{\text {max, }}$. AUC can be trusted most for describing absorption (the number of bioavailable drugs) $[23,24]$.

Table 9: The pharmacokinetics parameters of rifampicin

\begin{tabular}{lll}
\hline Pharmacokinetics parameter ${ }^{*}$ & Generic & Reference \\
\hline $\mathrm{k}_{\text {el }}($ per hour$)$ & $0.21 \pm 0.01$ & $0.21 \pm 0.02$ \\
$\mathrm{t}_{1 / 2}(\mathrm{~h})$ & $3.30 \pm 0.14$ & $3.47 \pm 0.29$ \\
$\mathrm{AUC}_{\mathrm{t}}\left(\mu \mathrm{g}^{*} \mathrm{~h}^{*} / \mathrm{ml}\right)$ & $29.16 \pm 4.05$ & $27.20 \pm 3.98$ \\
$\mathrm{AUC} \infty(\mu \mathrm{g} \mathrm{h} / \mathrm{ml})$ & $29.41 \pm 4.07$ & $27.49 \pm 4.01$ \\
$\mathrm{t}_{\max }(\mathrm{h})$ & $1.25 \pm 0.13$ & \\
$\mathrm{C}_{\max }(\mu \mathrm{g} / \mathrm{ml})$ & $5.81 \pm 0.88$ & \\
\hline
\end{tabular}

*Note: all pharmacokinetic parameters were expressed as mean \pm SEM obtained from 8 subjects, SEM was the standard error of the mean, The result of the statistical test using variance analysis (ANOVA) for two-way cross design considering the source of variations in drug products and the period of drug administration was provided in table 10.

Table 10: The Result of the statistical calculation of pharmacokinetics parameter of the test tablet " $X$ " and Reference tablet " $R$ "

\begin{tabular}{lll}
\hline The parameter of pharmacokinetics & Ratio of generic to reference & $\mathbf{9 0 \%}$ CI ratio \\
\hline $\mathrm{AUC}_{\mathrm{t}}$ & $106.86 \%$ & $99.13-120.02 \%$ \\
$\mathrm{AUC}$ & $106.90 \%$ & $98.87-119.80 \%$ \\
$\mathrm{C}_{\max }$ & $110.17 \%$ & $97.96-129.48 \%$ \\
\hline
\end{tabular}

Note: CI was a confidence interval 


\section{Bioequivalence criteria}

Geometric Average Ratio $(\mathrm{AUC})_{\mathrm{T}} /(\mathrm{AUC})_{\mathrm{R}}=1.00$ with $90 \% \mathrm{CI}=$ $80.00-125.00 \%$

Geometric Average Ratio $\left(\mathrm{C}_{\max }\right)_{\mathrm{T}} /\left(\mathrm{C}_{\max }\right)_{\mathrm{R}}=1.00$ with $90 \% \mathrm{CI}=$ 75.00-130.00\%

Based on the calculation result in table 10, it can be concluded that those rifampicin tablets met bioequivalence criteria.

\section{CONCLUSION}

The studied method was successfully applied in the bioequivalence study of rifampicin tablet using eight healthy subjects.

The mean values of $\mathrm{AUC}_{0-12}$ were $29.16 \pm 4.05 \mu \mathrm{g}^{*} \mathrm{~h} / \mathrm{ml}$ and $27.20 \pm 3.98 \mu \mathrm{g} * \mathrm{~h} / \mathrm{ml}$, respectively for generic and reference tablet. Meanwhile, the mean values of $\mathrm{C}_{\max }$ and $\mathrm{t}_{\max }$ for generic tablet were $5.808 \pm 0.880 \mu \mathrm{g} / \mathrm{ml}$ and $1.25 \pm 0.13 \mathrm{~h}$, respectively. In addition, the mean values of $\mathrm{C}_{\max }$ and $\mathrm{t}_{\max }$ for reference tablet were $5.036 \pm 0.545$ $\mu \mathrm{g} / \mathrm{ml}$ and $1.31 \pm 0.13 \mathrm{~h}$.

The generic rifampicin tablet " $\mathrm{X}$ " was bioequivalent to "Rimactan" tablet as a reference tablet, since the geometric average ratios of $(\mathrm{AUC})_{\mathrm{T}} /(\mathrm{AUC})_{\mathrm{R}}$ and $\left(\mathrm{C}_{\max }\right)_{\mathrm{T}} /\left(\mathrm{C}_{\max }\right)_{\mathrm{R}}$ within the acceptance criteria. Both products can be applied interchangeably in clinical treatment.

\section{ACKNOWLEDGMENT}

We would like to thank to the Ministry of Research, Technology, and Higher Education for providing funding for this research through the flagship scholarship for Higher Education of the fiscal year of 20152016 based on the Contract No. PUPT $92 / \mathrm{l} \mu \mathrm{G} / \mathrm{ml} / 2015$ and No. 815/UN1-P. III/IT/DIT-LIT/2016 awarded to Endang Lukitaningsih. We would also like to thank to UGM Hospital that has provided us with facilities for the bioequivalence test.

\section{AUTHORS CONTRIBUTIONS}

EL has a role as a project manager, along with RBP and FJ who are responsible for Bioanalysis. RDP, TR and ZI are responsible for the clinical test and blood sample collection in the hospital.

\section{CONFLICT OF INTERESTS}

All authors report no conflicts of interest in this research

\section{REFERENCES}

1. WHO. Global Tuberculosis Report 2013:WHO Press, Geneva; 1.

2. Maggi N, Pasqualucci CR, Ballota R, Sensi P. Rifampicin: A New Orally Active Rifamycin, Chemotherapia 1966;11:285-92.

3. Health Ministry of Republic Indonesia. Tuberkulosis Temukan Obat Sampai Sembuh, Pusat Data dan Informasi Kementrian Kesehatan Republik Indonesia. Jakarta; 2016. p. 2.

4. Hartkoorn RC, Chandler B, Owen A, Ward SA, Bertel SS, Back DJ, et al. Differential drug susceptibility of intracellular and extracellular tuberculosis, and the impact of P-glycoprotein. Tuberculosis (Edinb) 2007;87:248-55.

5. Health Ministry of Republic Indonesia. Formularium Nasional. Keputusan Menteri Kesehatan Republik Indonesia Nomor 328/Menkes/SK/VIII/2013. Jakarta; 2013.

6. Peloquin CA. Therapeutic Drug Monitoring in the Treatment of Tuberculosis. Drugs 2002;62:2169-83.

7. Panchagnula $\mathrm{R}$ and Agrawal S. Biopharmaceutic and Pharmacokinetic Aspects of Variable Bioavailability of Rifampicin. Int J Pharm 2004; 27:1-4.

8. Argekar AP, Kunjir SS, Purandare KS. Simultaneous Determination of Rifampicin, Isoniazid and Pyrazinamide by high-performance thin chromatography. J Pharm Biomed Anal 1996;14:1645-50.

9. Hartkoorn RC, Khoo S, Back DJ, Tjia JF, Waitt CJ, Chaponda M, et al. A rapid and sensitive HPLC-MS method for the detection of plasma and cellular rifampicin. J Chromatogr B 2017;857:76-82.

10. Srivastava A, Waterhouse D, Ardrey A, Ward SA. Quantification of rifampicin in human plasma a cerebrospinal fluid by the highly sensitive and rapid chromatographic-tandem mass spectrometric method. J Pharm Biomed Anal 2012;70:523-8.
11. Hee KH, Seo JJ, Lee LS. Development and validation of liquid chromatography-tandem mass spectrometry method for simultaneous quantification of first-line tuberculosis drugs and metabolites in human plasma and its application in the clinical study. J Pharm Biomed Anal 2015;102:253-60.

12. Allanson AL, Cotton MM, Tettey JNA, Boyter AC. Determination of rifampicin in human plasma and blood spots by highperformance liquid chromatography with uv detection: a potential method for therapeutic drug monitoring. J Pharm Biomed Anal 2007;44:963-9.

13. Van Ewijk Beneken KEWJ, Teulen MJA, van den Hombergh ECA, van Erp NE, Te Brake LHM, Aarnoutse RE. Determination of protein unbound, active rifampicin in serum by ultrafiltration and ultra-performance liquid chromategraphy with UV detection. A method was suitable for standard and high doses of rifampicin. J Chromatogr B 2017;1063:42-9.

14. The European Medicines Agency. Guideline for good clinical practice E6 (R2). Available from: http://www.ema.europa.eu/ docs/en_GB/document_library/Scientific_guideline/2015/08/ WC500191488.pdf. [Last accessed on 13 Mar 2019].

15. International Conference on Harmonization. Guidance on Validation of Analytical Procedure Methodology ICH Q2 (R1), Geneva, Switzerland; 2005.

16. Chan CC, Lam H, Lee YC, Zang XM. Analytical method validation and instrument performance verification. Canada: John Wiley and Sons, Inc; 2004. p. 16-24.

17. United States Pharmacopeia and National Formulary. USP-30 NF-25. Asian Edition. Rockville, MD: United States Pharmacopeia Convention; 2007.

18. Sharma S, Goyal S, Chauhan K. A review on analytical method development and validation. Int J Appl Pharm 2018;10:8-15.

19. Snyder LR, Kirkland JJ, Dolan JW. Introduction to modern liquid chromatography. 3th Ed. United States of America: John Wiley and Sons, Inc. Publication; 2010.

20. Ahuja S, Dong MW. Handbook of Pharmaceutical Analysis by HPLC Separation Science and Technology. 1st Ed.: Elsevier; 2005.

21. González AG, Herrador MA, Asuero AG. Intra-laboratory assessment of method accuracy (Trueness and Precision) by using validation standards. Talanta 2010;82:1995-8.

22. Mukti AA, Jannah F, Nurrochmad A, Lukitaningsih E. Development and validation method for quantitative determination of ciprofloxacin in human plasma and its application in bioequivalence test. Asian J Pharm Clin Res 2016;9:89-95.

23. World Medical Association. Declaration of Helsinki: Recommendations Guiding Physicians in Biomedical Research Involving Human Patients. Edinburgh; 2000.

24. International Conference on Harmonization (ICH) Expert Working Group. ICH Harmonized Tripartite Guideline. Guideline for Good Clinical Practice E6 (R1). Geneva; 1996.

25. Organization for Economic Co-operation and Development (OECD). OECD Series on Principles of Good Laboratory Practice and Compliance Monitoring. Number 1. Revised. Paris; 1997.

26. Indonesian Agency of Drug and Food Monitoring. Pedoman Uji Bioekuivalensi. [Indonesian Guideline for Bioequivalence Studies]. Jakarta: BPOM; 2005. Available from: http://jdih.pom.go.id/ showpdf.php?u=89. [Last accessed on 10 Mar 2018].

27. Indonesian Agency of Drug and Food Monitoring. Peraturan Kepala BPOM RI Nomor. HK.03.1.23.12.11.10217. Tentang Obat Wajib Uji Bioequivalensi [BPOM-RIofgulation for Drugs Compulsory for Bioequivalence Studies]. Jakarta: BPOM; 2011. Available from: http://jdih.pom.go.id/showpdf.php?u=97. [Last accessed on 10 Mar 2018.

28. Cruz DD, Babu A, Joshy E, Anesh TP. Bioanalytical method development and validation of ticagrelor by RP-HPLC. Int J Appl Pharm 2017;9:51-4.

29. Shah U, Jasani A. UV spectrophotometric and RP HPLC methods for simultaneous estimation of isoniazid, rifampicin and piperine in the pharmaceutical dosage form. Int J Pharm Pharm Sci 2014;6:273-80.

30. Siddartha TS, Prasanthi B, Santosh T, Ratna JV. Development and validation of high performance liquid chromatographic method for the determination of rifampicin in human plasma. Int J Pharm Pharm Sci 2012;4 Suppl 5:362-7. 